\title{
Toward Understanding the Structure of the Historical Controversy: Atomic Models as an Exemplar
}

\author{
Sangwoon Kwon ${ }^{1}$, Gyoungho Lee ${ }^{1 *}$, Mansoor Niaz ${ }^{2}$ \\ ${ }^{1}$ Department of Physics Education, Seoul National University, SOUTH KOREA \\ 2 Department of Chemistry, Universidad de Oriente, VENEZUELA \\ Received 14 August 2019 • Accepted 27 July 2020
}

\begin{abstract}
Many researchers have suggested that incorporating history and philosophy of science in the science curriculum can be helpful for students' understanding of scientific concepts and effective for developing their scientific thinking. Recently, in this context, there have been studies on historical controversies which show that history of science promotes debate and controversy and thus sustains students' effort to understand what is being taught. However, existing studies have only searched and selected what the historical controversial issues exist and have not dealt with more practical issues such as how to use them in the classroom. In this study, for finding guide to teach controversial issues in history of science, we analyzed controversial issues related to the structure of the atom to understand their structure by using the 'framework of knowledge and belief'. As a result, it was confirmed that the structures of the historical controversies consisted of various forms from the conceptual level to the belief level. Finally, the implications related to the use of the result of this study in the classroom, and to science education research were discussed.
\end{abstract}

Keywords: atomic structures, HPS, controversies, conflict analysis

\section{INTRODUCTION}

The current emphasis in science education which has focused attention on the nature of science (NOS), the processes of science, and scientific inquiry rather than the overbearing transmission of canonical scientific knowledge, has gradually given rise to a science education reform at secondary and university levels. Hodson (1988) had pointed out that in general science education has narrowly focused on goals related solely to content knowledge acquisition rather than either understanding the nature of science or developing thinking and scientific attitudes. More recently, Hodson (2009) has explicitly recommended the inclusion of NOS in the science curriculum. School science education can also be haphazard and bring about unintended consequences, such as providing students with a distorted or even falsified image of science. Therefore, many researchers have emphasized teaching the nature of science and scientific procedure explicitly. Jenkins (1989), for instance, argued that what we teach to students should not just comprise "technical" scientific knowledge but also the means of doing science itself.

Following this line of thinking, there has been an emphasis placed upon using the history of science for educating students about the nature of science and scientific methodology. Matthews (2015) emphasized that it is necessary to adopt history of science education suggesting six reasons for adopting history of science. ${ }^{1}$

${ }^{1}$ Matthews explained reasons for including a historical component in science programs as follows. (Matthews, 2015, p.107)

1) History promotes the better comprehension of scientific concepts and methods.

2) Historical approaches connect the development of individual thinking with the development of scientific ideas.

3) History of science is intrinsically worthwhile. Important episodes in the history of science and culture should be familiar to all students.

4) History is necessary to understand the nature of science.

5) History, by examining the life and times of individual scientists, humanizes the subject matter of science, making it less abstract and more engaging for students.

6) History allows connections to be made within topics and disciplines of science, as well as with other academic disciplines; history displays the integrative and interdependent nature of human achievements.

(c) $\mathbf{2 0 2 0}$ by the authors; licensee Modestum. This article is an open access article distributed under the terms and conditions of the Creative Commons Attribution License (http://creativecommons.org/licenses/by/4.0/).

$\square$ white001@snu.ac.kr $\square$ ghlee@snu.ac.kr (*Correspondence) $\square$ niazma@gmail.com 


\section{Contribution to the literature}

- The result of this study helps us to understand structures of historical controversial issues about atomic structure developed by Niaz (Niaz, 1998).

- The framework and result of this study can be a guideline for developing physics lessons or textbooks orientated toward representing scientists' practices itself.

Sequeira and Leite (1991) showed that there is an intimate connection between conceptual development in history of science and that conceptual development of individual students and suggested educational applications of using history of science. Kim and Irving (2010) offered a model illustrating the relation among scientific content knowledge, nature of science and history of science, and then showed that history of science can play an important role for students when acquiring scientific knowledge and comprehending nature of science. Nahum (2001) has provided a case study of Volta and showed that learning about a historical controversy may improve students' understanding of how scientists defend a new theory. Matthews (2015) thought that the history of science can bring students closer to physics since the acknowledgement of controversy gave those contents a significance that was fundamental to its understanding. Rodríguez and Niaz (2002) argued that history of physics itself allows for debate by stimulating controversy and thus sustaining students' attitudes and efforts to understand what is being taught. More recently, Niaz (2009) has highlighted that the analysis of these historical controversies, motivated by philosophical questions, is fundamental to the understanding of the development of how science progresses and hence, to scientific education.

Similarly, philosophers of science have also recognized the crucial role played by controversies in scientific progress:

Many major steps in science, probably all dramatic changes, and most of the fundamental achievements of what we now take as the advancement or progress of scientific knowledge have been controversial and have involved some dispute or another. Scientific controversies are found throughout the history of science. This is so well known that it is trivial. What is not so obvious and deserves attention is a sort of dissociation between science as actually practiced and science as perceived or depicted by both scientists and philosophers. (Machamer et al., 2000, p. 3)

It is precisely this lack of attention to how scientists practice science that textbooks generally ignore the importance of controversies and how these can help to motivate students' interest in science and draw attention to the human nature of science (Niaz, 2010).
In this context, Niaz (1998) argued that the reconstruction of historical controversies is an essential element for effective student learning, rather than the all too common 'rhetoric of conclusions' approach - where temporary constructions of scientific knowledge are conveyed as empirical, literal, and irrevocable truths. $\mathrm{He}$ has provided several important criteria for examining how controversies are typically dealt with in textbooks, looking especially at chapters which deal with the development of the structure of the atom, and contrasting the story told there with perspectives as presented in history and philosophy of science (HPS) studies. Many general physics and chemistry textbooks published in Turkey and U.S.A. were analyzed based on these criteria (Niaz \& Coştu, 2009; Rodríguez \& Niaz, 2002). These studies show that most textbooks almost completely neglect historical controversies, which actually accompanied the history of the atom and theory change, and which they misleadingly purport to discuss and represent. In recent study, similarly, Niaz, Kwon, Kim, and Lee (2013) analyzed the Korean general physics textbooks written by Korean authors, with criteria suggested by Niaz (1998). The result of the study was not significantly different from that of U.S.A. or Turkey. Most of the Korean textbooks do not include the historical controversies in chapter of atomic structure.

From an educational perspective, however, these historical controversial issues, suggested by Niaz, arouses some regrets. First, it needs a guide on how to use in science class. The most concerned side effect in science class utilizing the history of science is that the historical events could become another knowledge to 'remember' for students. Therefore, teachers who should interact with students in classroom need specific guide on how to understand controversial issues and how to teach them. Second, it needs a way to find significant historical controversial issues related to scientific topics other than the structure of the atom. If the controversial issue in the history of science is educationally important, it should be possible to find controversial issues in other scientific subjects besides the structure of the atom. However, Niaz's research does not suggest how to explore these issues and select with certain criteria. Therefore, teachers or researchers have no choice but to wait for Niaz and other related researchers to set other controversial issues. However, if teachers or researchers of science education themselves can explore and select controversial issues with common criteria, researches and classes, related to controversial issues of history of science, could develop more actively. 


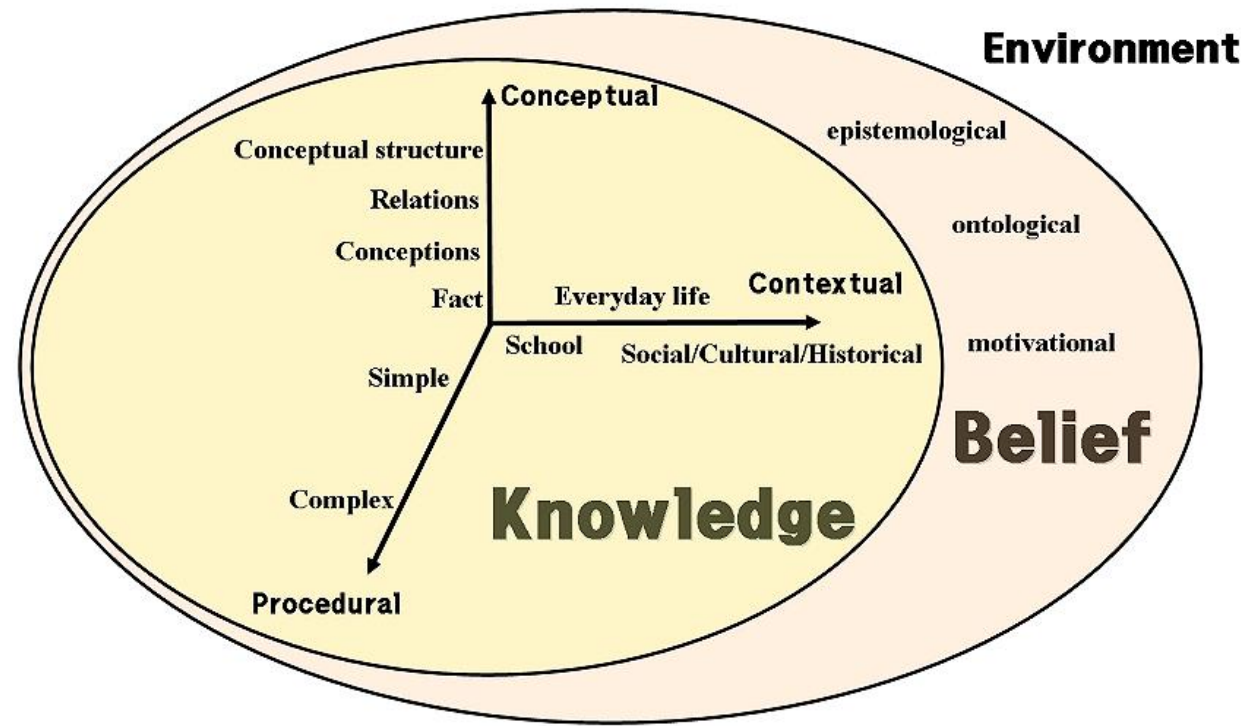

Figure 1. Framework of knowledge and belief

Therefore, in this context, this study focused on the following research questions. A) What should be understood and what should be emphasized in utilizing scientific historical controversial issues in science class? B) What are the tools to find educationally meaningful controversial issues in the history of science related to scientific topics other than the structure of the atom? In this study, the framework of knowledge and belief developed by Lee and Yi (2013) was applied to solve these two research problems particularly, to analyze and understand historical controversial issues by visualizing the structure of them. Because visualizations based on graphical representations allow holistic understanding that words alone cannot convey (Jones, Pierce, \& Hunter, 1988-89), it can be expected, using this framework, to know the parts and the whole in a way that is not available in the sequential structure of a text.

\section{RESEARCH METHODOLOGY}

\section{Analysis Tool: Framework of Knowledge and Belief}

To analyze the structure of historical controversy, we have used the framework of knowledge and belief suggested by Lee and Yi (2013). This framework was originally developed in order to analyze the structure of creating students' cognitive conflict. In this framework, there are three major resources which may create students' cognitive conflict; knowledge, belief and environment. Each of the resources has some subcomponents. For instance, in the case of knowledge, there are three subcomponents: conceptual, contextual and procedural knowledge. Conceptual knowledge is a resource related to fact, conceptions, conceptual relations, and conceptual structure. Contextual knowledge is related to the use of specialized knowledge in specific social, cultural, and historical context. Procedural knowledge includes making use of information and one's ability to learn science. In the case of belief, we can consider three type of belief: epistemological, ontological, and motivational belief. Epistemological belief is about how people view their own knowledge. This belief considers how they look inward and make qualitative judgments and commitments about various theories and conceptions they might have. Ontological belief is about how people view the outside world, in other words, how they look from within to the outside.

This framework can be used in various context in science education. By checking certain points in the space of the framework, we can understand the cognitive states or conflicts in students' minds. For example, in students' leaning context, it helps us to understand where the conceptual conflicts are arisen from. On the other hand, in teaching context, it helps teachers to make teaching strategy considering various types of knowledge and belief. In this study, we use this framework for analyzing the structure of the historical controversies: what components have an antagonistic relationship with each other.

\section{Analyzing Historical Controversies}

In this study, controversy was defined as the conflict between subcomponents in the framework of knowledge and belief. In other words, a controversy has arisen from the conflict between different knowledge and belief structures. Since 1990, Niaz has studied the historical controversies in physics and chemistry. Following is a brief summary of historical controversies about development of atomic structure, as suggested by Niaz (1998, p. 541-542).

T1 - Cathode rays as charged particles or waves in the ether. Thomson's experiments were conducted against the backdrop of a conflicting 
framework. Thomson (1897) explicitly pointed out that his experiments were conducted to clarify the controversy with regard to the nature of the cathode rays; that is, charged particles or waves in the ether.

T2 - Determination of mass-to-charge ratio to decide whether cathode rays were ions or a universal charged particle. Thomson decided to measure mass-to-charge ratio to identify cathode rays as ions (if the ratio was not constant) or as a universal charged particle (constant ratio for all gases).

R1 - Nuclear atom. Rutherford's experiments with alpha particles and the resulting model of the nuclear atom had to compete with a rival framework, namely Thomson's model of the atom (referred to as "plum-pudding" in most textbooks).

R2 - Probability of large deflections is exceedingly small as the atom is the seat of an intense electric field. The crucial argument that clinched the argument in favor of Rutherford's model was not the large angle deflection of alpha particles (an important finding), but rather the knowledge that 1 in 20,000 particles deflected through large angles.

R3 - Single/compound scattering of alpha particles. To maintain his model of the atom and to explain large angle deflections of alpha particles, Thomson put forward the hypothesis of compound scattering (multitudes of small scatterings). The rivalry between Rutherford's hypothesis of single scattering based on a single encounter and Thomson's hypothesis of compound scattering led to a bitter dispute between the proponents of the two hypotheses.

B1 - Paradoxical stability of the Rutherford model of the atom. Bohr's main objective was to explain the paradoxical stability of the Rutherford model of the atom, which constituted a rival framework for his own model.

B2 - Explanation of the hydrogen line spectrum. Bohr had not even heard of the Balmer and Paschen formulas for the hydrogen line spectrum, when he wrote the first version of his 1913 article. Failure to understand this episode within a historical perspective led to an inductivist / positivist interpretation, referred to as the "Baconian inductive ascent" by Lakatos (1970). Interestingly, Kuhn and Lakatos, in spite of their so many differences, agreed that Bohr's major contribution was the quantization of the Rutherford model of the atom.
B3 - Deep philosophical chasm. Bohr's incorporation of Planck's "quantum of action" to the classical electrodynamics of Maxwell, represented a strange "mixture" for many of Bohr's contemporaries and philosophers of science. This episode illustrates how scientists, when faced with difficulties, often resort to such contradictory "grafts."

These historical controversies were analyzed by identifying their structure. The components and subcomponents of framework of knowledge and belief were identified in each controversy. These components then facilitated the construction of the structure of the conflicting relation.

For example, if the controversy represents the conflict between two conceptual knowledge subcomponents, it would be identified as type $\mathrm{K}_{\mathrm{C}}-\mathrm{K}_{\mathrm{C}}$. The notation ' $\mathrm{K}_{\mathrm{C}}$ ' means conceptual knowledge. Similarly, if the controversy represents the conflict between conceptual knowledge and procedural knowledge, it would be identified as $\mathrm{K}_{\mathrm{C}}-\mathrm{K}_{\mathrm{P}}$. In this type, the notation ' $\mathrm{K}_{\mathrm{P}}$ ' means procedural knowledge. In this study, the knowledge related with respect to experiments such as data or interpreting the experimental data is considered procedural knowledge. And if the controversy represents the conflict between different frameworks of knowledge and belief, its types would be identifying as type KB-K' $\mathrm{B}^{\prime}$. In this case, KB means the whole of knowledge and belief framework. On the other hand, $\mathrm{K}^{\prime} \mathrm{B}^{\prime}$ means the different kind of knowledge and belief framework. Therefore, the controversy type $K B-K^{\prime} B^{\prime}$ includes the conflict not only in knowledge level, but in belief level (e.g. conflict between two different paradigms). In this way, 8 historical controversies were analyzed, and their structure type was identified.

The following procedure was used to establish the reliability of analyzing controversies. First stage authors and one science education researcher reviewed the historical controversies suggested by Niaz (1998) and analyzed them with the framework of knowledge and belief, respectively. The researchers who conducted the analysis have experience in analyzing various science textbooks, and also have expertise in the history and philosophy of science. They looked into the historical controversies related to the structure of the atom and extracted the key conflict elements to construct the conflict structure of each controversy. Second Stage researchers shared their result of analysis. Then after several discussion, the results of the analysis of the conflict structure of each controversy within the framework of knowledge and belief were completed.

\section{RESULTS}

The results of this research which analyzed and visualized the structure of controversies are follows. 


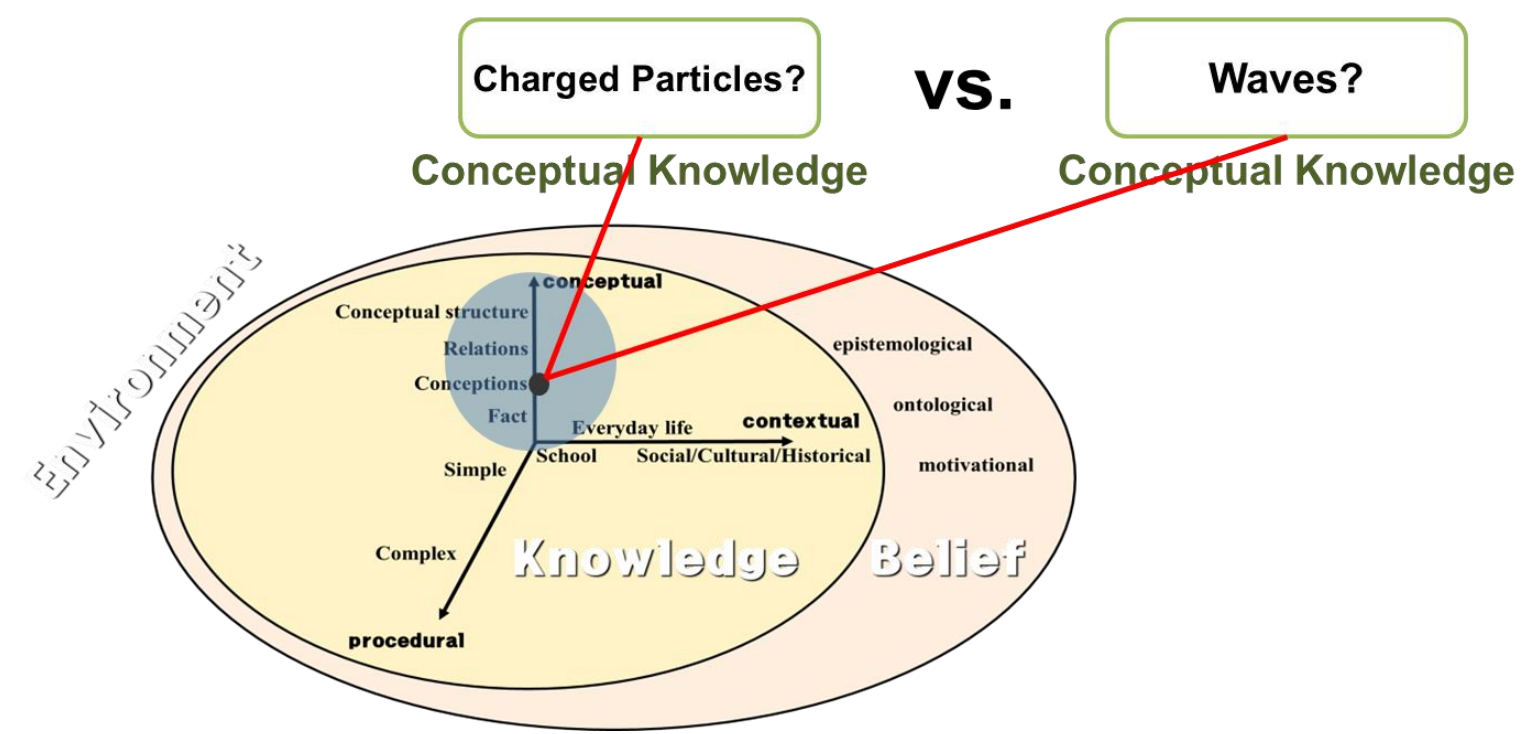

Figure 2. The structure of controversy T1

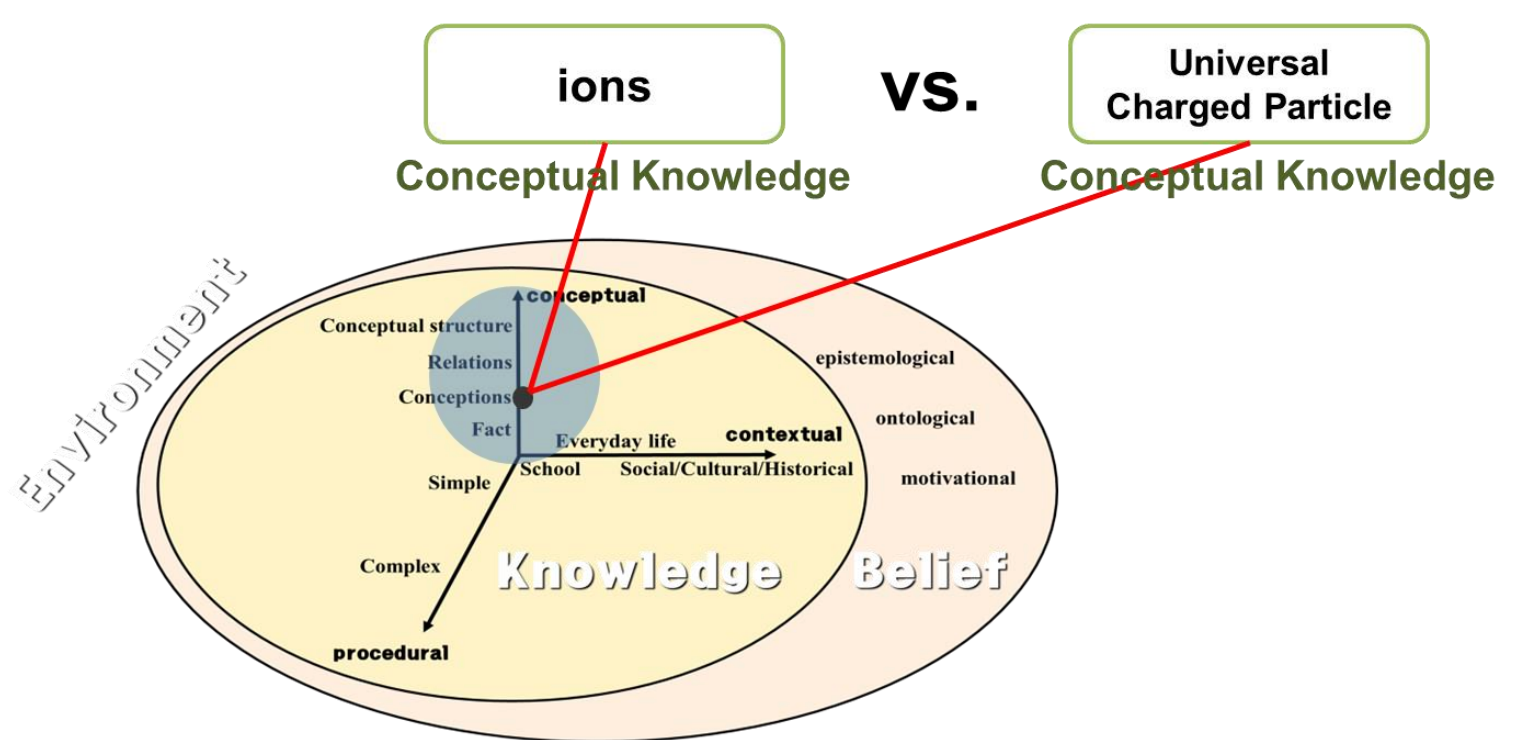

Figure 3. The structure of controversy T2

\section{Controversy T1}

In case of $\mathrm{T} 1$, there is a controversy about the nature of cathode rays. Niaz explained this controversy as follows,

\section{“Thomson's experiments were conducted against the backdrop of a conflicting framework. Thomson (1897) explicitly points out that his experiments were conducted to clarify the controversy with regard to the nature of the cathode rays; that is, charged particles or waves in the ether." (Niaz, 1998, p. 541)}

This shows the conflict between two concepts about cathode rays. One is particle, the other is wave. This controversy arose from the conflict between two conceptual knowledge frameworks; particle concept versus wave concept. Therefore, it can be identified as $\mathrm{K}_{\mathrm{C}}-\mathrm{K}_{\mathrm{C}}$ type.

\section{Controversy T2}

T2 controversy is about the nature of cathode ray particles.

\footnotetext{
"Thomson decided to measure mass-to-charge ratio to identify cathode rays as ions (if the ratio was not constant) or as a universal charged particle (constant ratio for all gases)." (Niaz, 1998, p. 541)
}

This shows that there is a conflict between two different concepts about cathode rays particle; ions versus a universal charged particle. These are subcomponents of conceptual knowledge. Therefore, it can be identified as $\mathrm{K}_{\mathrm{C}}-\mathrm{K}_{\mathrm{C}}$ type.

\section{Controversy R1}

R1 controversy shows a conflict between the atomic model of Rutherford and that of Thomson. 


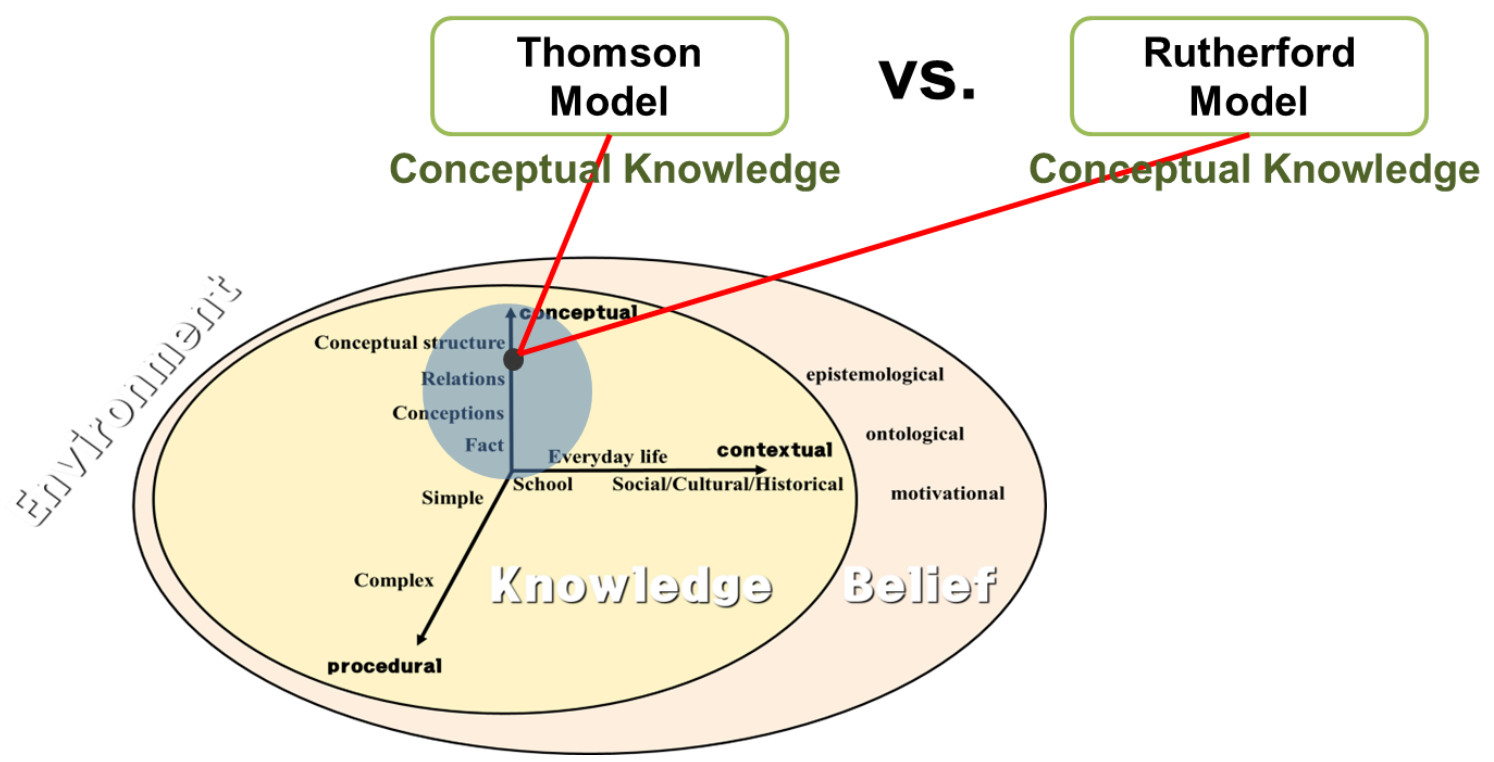

Figure 4 . The structure of controversy R1

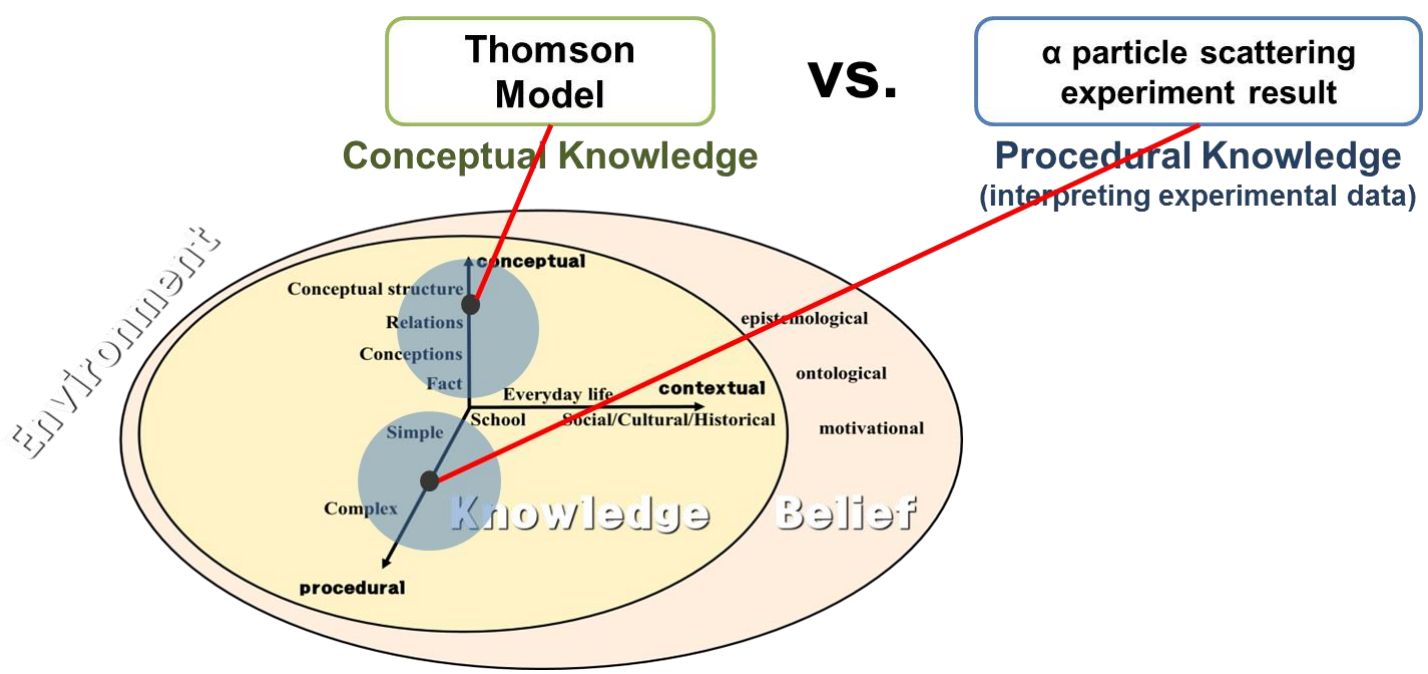

Figure 5. The structure of controversy R2

"Rutherford's experiments with alpha particles and the resulting model of the nuclear atom had to compete with a rival framework, namely Thomson's model of the atom (referred to as "plum-pudding" in most textbooks)." (Niaz, 1998, p. 541)

In this controversy, there are two conflicting models. Atomic models are related to conceptual knowledge. However, it is different from simple concepts. An atomic model is much more complicated conceptual knowledge. It includes the concepts of particles, the relationship between them, and the structure and motions of them. Therefore, the structure type of this controversy is $\mathrm{K}_{\mathrm{C}}-\mathrm{K}_{\mathrm{C}}$. However, the character of this controversy is different from previous controversies (T1 or T2) with respect to conceptual knowledge.

\section{Controversy R2}

R2 controversy includes Rutherford's alpha particle scattering experiment.

\footnotetext{
"The crucial argument that clinched the argument in favor of Rutherford's model was not the large angle deflection of alpha particles (an important finding), but rather the knowledge that 1 in 20,000 particles deflected through large angles." (Niaz, 1998, p. 541)
}

This controversy emphasizes that the result of Rutherford's experiment was different from what he expected, based on Thomson's atomic model. Thomson's atomic model is related with conceptual knowledge, specifically the conceptual structure. On the other hand, Rutherford's interpretation of experimental data is related with procedural knowledge. Therefore, we can identify the structure type of this controversy as $\mathrm{K}_{\mathrm{C}}-\mathrm{K}_{\mathrm{P}}$. 


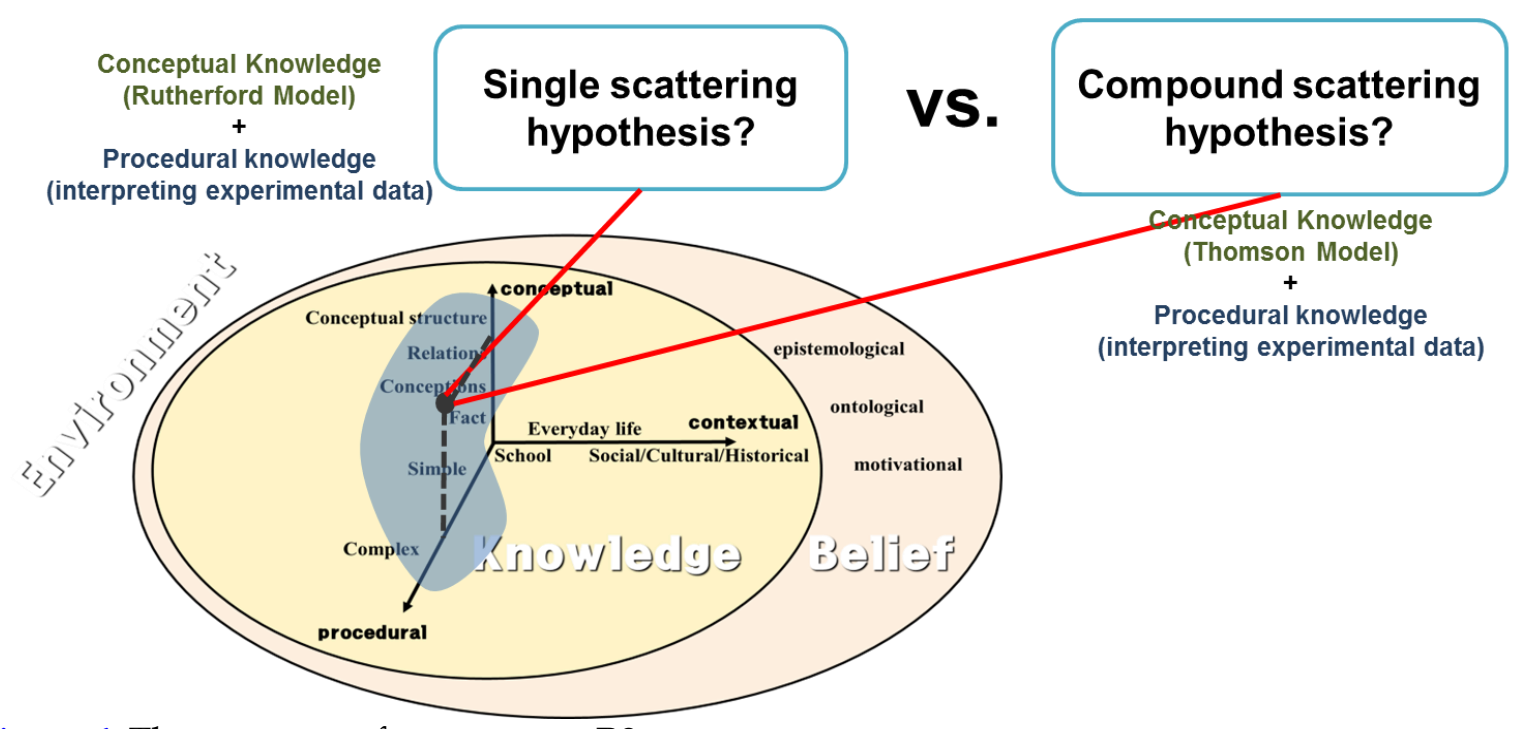

Figure 6. The structure of controversy R3

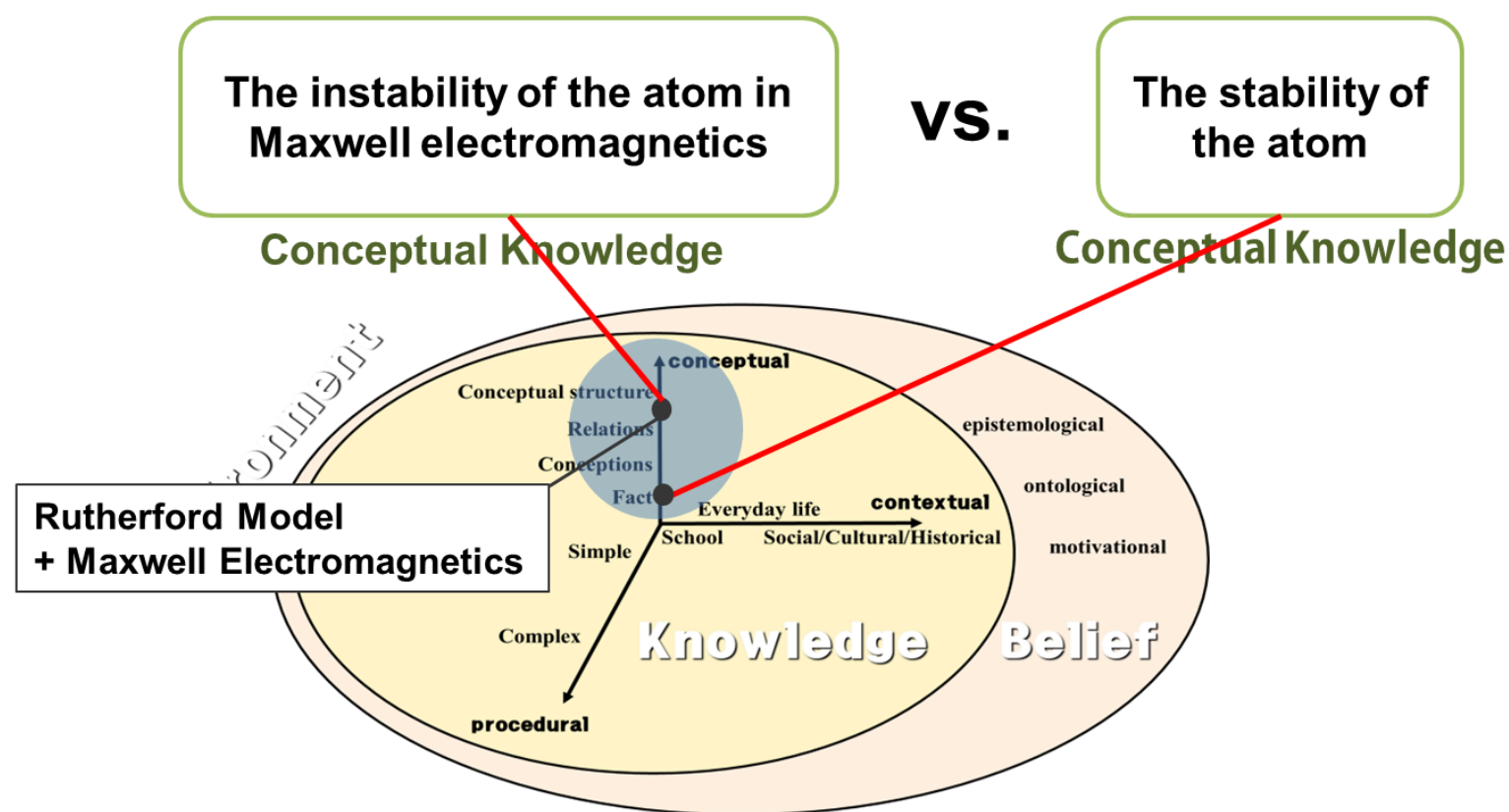

Figure 7. The structure of controversy B1

\section{Controversy R3}

R3 controversy shows a conflict between two different hypotheses for interpreting results of alpha particle scattering experiments.

"To maintain his model of the atom and to explain large angle deflections of alpha particles, Thomson put forward the hypothesis of compound scattering (multitudes of small scatterings). The rivalry between Rutherford's hypothesis of single scattering based on a single encounter and Thomson's hypothesis of compound scattering led to a bitter dispute between the proponents of the two hypotheses." (Niaz, 1998, p. 541-542)

In this controversy, there are two hypotheses for explaining Rutherford's experimental data. Thomson's or Rutherford's hypothesis includes the atomic model for interpreting the results of experimental data. An atomic model is the structure of concepts, related with conceptual knowledge. Interpreting experimental result is related with procedural knowledge. Therefore, we concluded that the hypothesis is a combination of conceptual knowledge and procedural knowledge. Hypothesis, in other words, is a conceptual structure for interpreting experimental data. Therefore the structure type of this controversy can be identified as $\mathrm{K}_{C, P}-\mathrm{K}_{C, P}$.

\section{Controversy B1}

B1 controversy shows the problematic nature of Rutherford's atomic model.

"Bohr's main objective was to explain the paradoxical stability of the Rutherford model of 


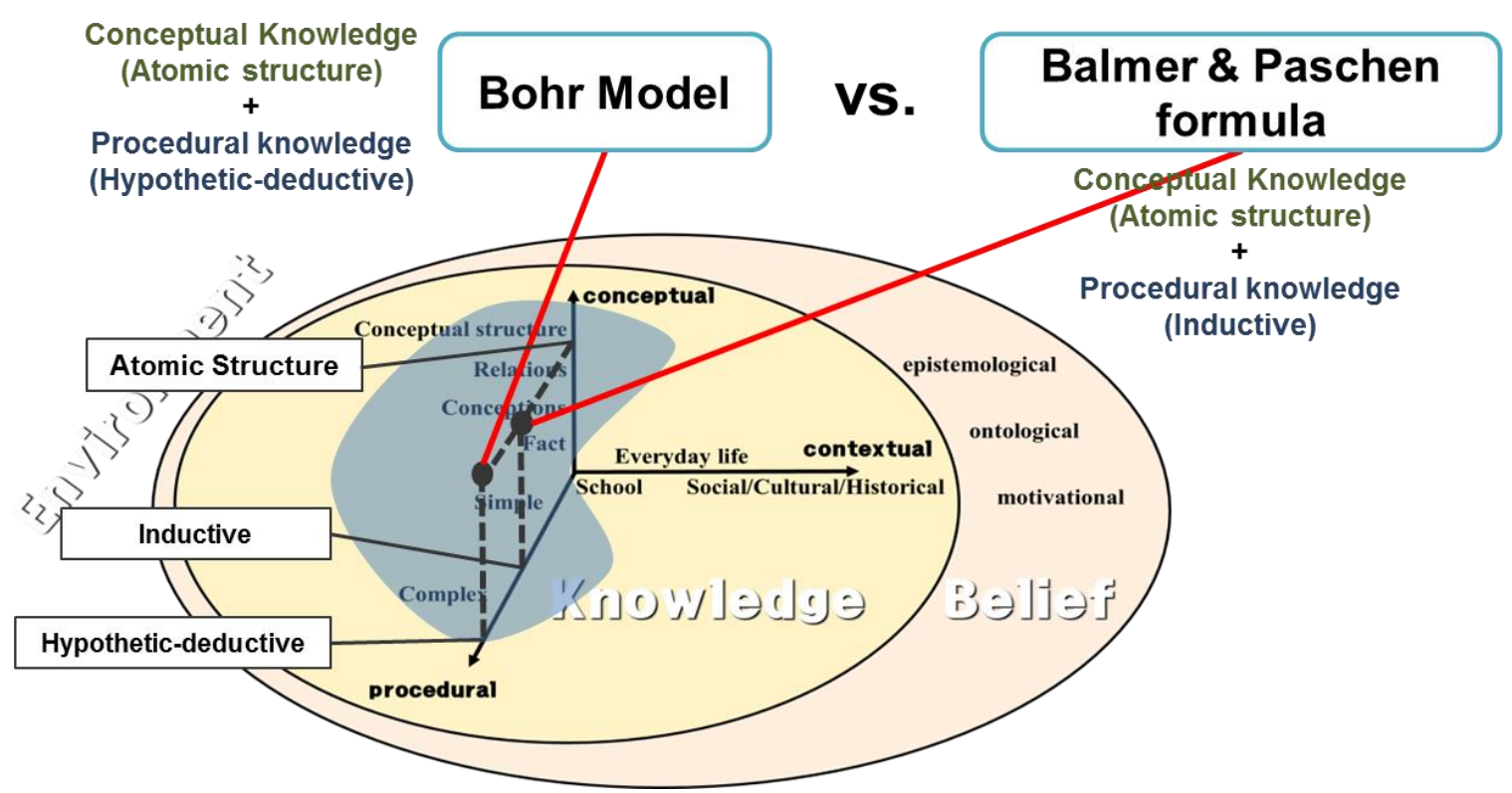

Figure 8. The structure of controversy B2

the atom, which constituted a rival framework for his own model." (Niaz, 1998, p. 542)

Niaz pointed out the problem about Rutherford's model. In Maxwell's electrodynamics, accelerated electrons in an atom radiates electromagnetic energy. By losing energy, the radius of electron would become smaller. Finally, the electron would collide with the nucleus and create an unstable atom. However, atoms actually exist stably. In this controversy, we can find the conflict between Rutherford's atomic model and the existence of real stable atoms. Rutherford's atomic model is the conceptual structure belonging to conceptual knowledge. The stability of real atom is the fact, also belonging to conceptual knowledge. Therefore, the structure type of controversy can be identified as $\mathrm{K}_{\mathrm{C}^{-}}$ $\mathrm{K}_{\mathrm{C}}$.

\section{Controversy B2}

B2 controversy highlights the importance of episodes related with Balmer and Paschen's formulas and Bohr.

\footnotetext{
"Bohr had not even heard of the Balmer and Paschen formulas for the hydrogen line spectrum, when he wrote the first version of his 1913 article. Failure to understand this episode within a historical perspective led to an inductivist / positivist interpretation, referred to as the "Baconian inductive ascent" by Lakatos (1970). Interestingly, Kuhn and Lakatos, in spite of their so many differences, agree that Bohr's major contribution was the quantization of the Rutherford model of the atom." (Niaz, 1998, p. 542)
}

Although Bohr did not meet/argue with Balmer/Paschen, still his contribution can be analyzed within a conflicting framework based on the following plausible explanations: a) Explanation of the paradoxical stability of the Rutherford model of the atom (hypothetico-deductive); b) Explanation of the hydrogen line spectrum based on the formulae of Balmer and Paschen (inductivist). This conflict is important as most general chemistry/physics textbooks and even some philosophers of science follow the inductivist explanation and ignore the hypothetico-deductive aspect of Bohr's contribution. One general chemistry textbook expressed the dilemma faced by Bohr in cogent terms:

Bohr said to classical physicists: "You have been misled by your physics to expect that the electron would radiate energy and spiral into the nucleus. Let us assume that it does not, and see if we can account for more observations than by assuming that it does" (Dickerson et al., 1979, pp. 294-295)

This clearly shows the importance of the hypotheticodeductive explanation. Therefore, this difference between the Balmer and Paschen formulas and Bohr can also be understood as a conflict, which includes conceptual and procedural knowledge components. In terms of procedural knowledge, Bohr's model had hypothetic-deductive approach, whereas Balmer and Paschen formulae had inductive approach. Consequently, similar to controversy R3, B2 controversy could be identified as $\mathrm{K}_{\mathrm{C}, \mathrm{P}}-\mathrm{K}_{\mathrm{C}, \mathrm{P}}$, by combining conceptual and procedural knowledge.

\section{Controversy B3}

B3 controversy treats conflict at the philosophical level.

"Bohr's incorporation of Planck's "quantum of action" to the classical electrodynamics of Maxwell, represented a strange "mixture" for 


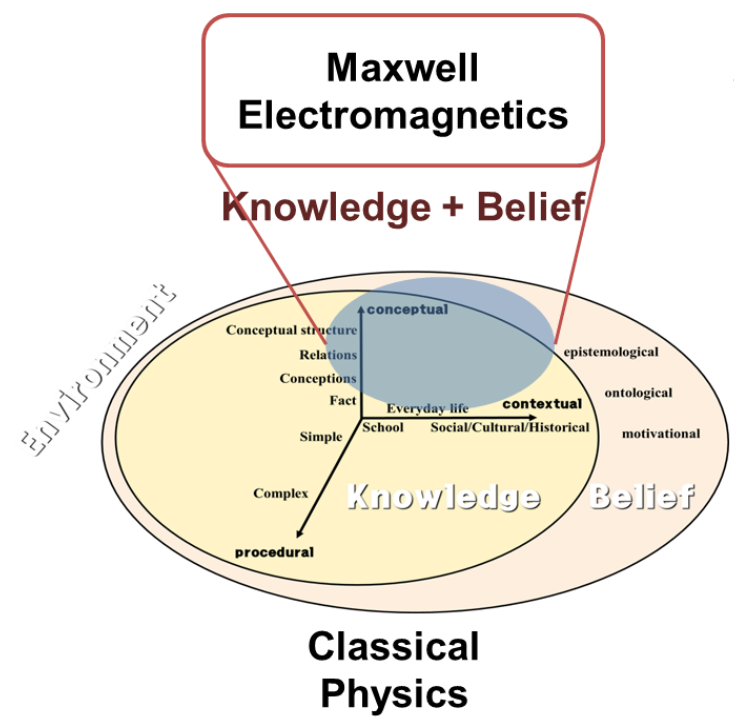

Figure 9. The structure of controversy B3

many of Bohr's contemporaries and philosophers of science. This episode illustrates how scientists, when faced with difficulties, often resort to such contradictory 'grafts'." (Niaz, 1998, p. 542)

This controversy shows two different frameworks of knowledge and belief. The one framework is based on classical physics. Most of Bohr's contemporaries and philosophers of science had this framework at that time. The other framework is based on quantum physics. Planck's idea of 'quantum of action' is the key idea of quantum physics. Bohr accepted this idea and applied it to his atomic model. In other words, Bohr had a different framework from that of other scientists or philosopher of science at that time. In this case there is a conflict between two different kinds of paradigm (framework of knowledge and belief), and therefore this controversy can be identified as $\mathrm{KB}-\mathrm{K}^{\prime} \mathrm{B}^{\prime}$. For instance, according to Niaz (1998):

An important aspect of Bohr's model of the atom is the presence of a deep philosophical chasm: that is, in the stationary states, the atom obeys classical laws of Newtonian mechanics; on the other hand, when the atom emits radiation, it exhibits discontinuous (quantum) behavior, according to laws first proposed by Planck in 1900. (p. 540)

\section{CONCLUSIONS \& DISCUSSIONS}

In this study, two research questions were: a) What should be understood and what should be emphasized in utilizing scientific historical controversial issues in science class? b) What are the tools to find educationally meaningful controversial issues in the history of science related to scientific topics other than the structure of the atom? To solve these research problems, the structures of historical controversies were identified and visualized by using the framework of knowledge and belief. As mentioned earlier, the graphical representation can provide us the holistic relationships of knowledge and belief related with a historical controversy. In other words, considering the relationships of diverse knowledge and belief components, it could be understood the nature of historical controversies more deeply via the structure of historical controversies visualized as graphical structure.

In addition to the advantage of visualized form, the structure of controversy provides more insight about historical controversies. Figure 10 shows the types of controversies in the history of atomic models.

Most of controversies arose from conflict between subcomponents in knowledge level. Particularly, there are many of $\mathrm{K}_{\mathrm{C}}-\mathrm{K}_{\mathrm{C}}$ types. However, it can be found that there are diverse kinds in $\mathrm{K}_{\mathrm{C}}-\mathrm{K}_{\mathrm{C}}$ types. Some of controversies identified as the structure $\mathrm{K}_{\mathrm{C}}-\mathrm{K}_{\mathrm{C}}$ arose from the conflict between different concepts. On the other hand, other $\mathrm{K}_{\mathrm{C}}-\mathrm{K}_{\mathrm{C}}$ controversies include the conceptual relations or structure. As time goes by, it can be seen that the controversies became more complex and structured. Historical controversies arose from not only conceptual knowledge level, but procedural knowledge level and even belief level. In case of Thomson, his main objective was identifying the nature of cathode rays (Controversies T1 and T2). Thomson was interested in atomic models and was fully aware that studying nature of the cathode rays would help him to do so. Therefore, the structure of controversies related with Thomson was identified in knowledge level, especially conceptual knowledge. However, in Rutherford's case, there are some additional. Controversy related with Rutherford's work included explanation of experimental data, and treatment of procedural knowledge. In other words, in case of Rutherford, controversies expanded from conflict between different conceptual knowledge $\left(\mathrm{K}_{\mathrm{C}}-\mathrm{K}_{\mathrm{C}}\right)$, between conceptual and procedural knowledge $\left(\mathrm{K}_{\mathrm{C}}-\mathrm{K}_{\mathrm{P}}\right)$, 
The types of controversy

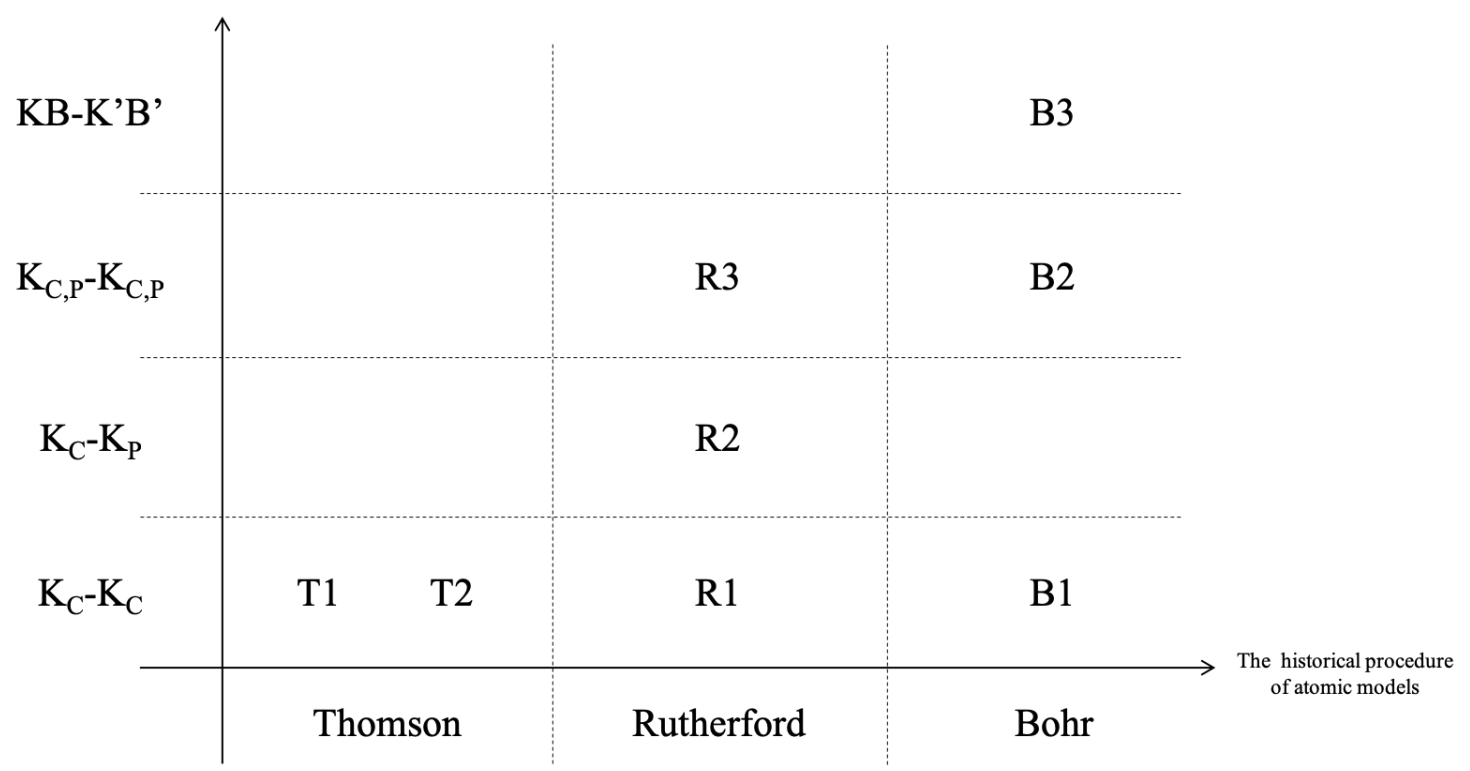

Figure 10. The controversy types in the history of atomic model $\left(\mathrm{K}_{\mathrm{C}}-\mathrm{K}_{\mathrm{C}}\right.$ : conflict between two conceptual

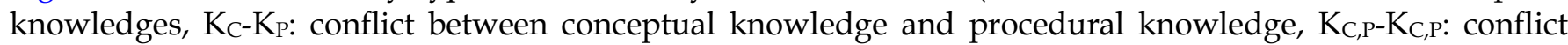
between two different combinations of conceptual knowledge and procedural knowledge, KB-K'B': conflict between two different knowledge-belief states)

to between different combinations of conceptual and procedural knowledge $\left(\mathrm{K}_{\mathrm{C}, \mathrm{P}}-\mathrm{K}_{\mathrm{C}, \mathrm{P}}\right)$. In the case of Bohr, controversies even include the belief level. Bohr introduced the concept 'quantum of action' as suggested by Planck. This idea has a different knowledge and belief framework from that of classical physics. Furthermore, Bohr didn't conduct any experiment for constructing his atomic model. Therefore, we can see that controversies related with Bohr jumped from conceptual knowledge level conflict (B1) to the combination of conceptual and procedural knowledge level conflict (B2). At the end, they expanded to the conflict (B3) between two different frameworks of knowledge and belief (under two different worldviews, respectively).

The results of this study show that most of scientific historical controversies related to the structure of atom have a conflict structure between conceptual knowledge elements. Considering existing studies about historical controversies in science education, the results of this study seem quite significant. Most of the studies argued that the scientific historical controversies should be introduced into the class in order to deal with the process of science or the epistemological problem of scientific knowledge, pedagogically. Taking the most recent studies as an example, Archila et al. (2020) argued for the use of historical controversies to improve students' ability to discuss. In particular, they emphasized the improvement of students' decision making and communication skills in relation to discussion ability, which has been emphasized at the scientific process level in science education research. Justi and Mendonça (2016) also suggested that through historical controversies, students can improve their ability to discuss and additionally understand various aspects of the production or use of scientific knowledge. Garritz (2013) said that by taking advantage of the controversies over the interpretation problem of quantum mechanics, students can understand the process of scientific knowledge formation; scientific knowledge is not formed merely by accumulation of experimental data. In addition, Niaz (2010), which emphasized the scientific historical controversies related with the structure of the atom, he strongly insisted that students should be taught as scientists do scientific practice.

On the other hand, the results of this study reveal that the process aspect of science is of course important, but the understanding of the conceptual aspect cannot be overlooked. For example, the T1 issue, a controversy over Thomson's discovery of electrons, was analyzed to have a conceptual conflict structure as to whether the nature of the cathode ray is a particle or a wave. Therefore, teachers or students must understand the concept of particles and waves accurately, in order to understand this T1 issue properly. Specifically, questions, such as "What is the concept of a particle and a wave?" and "What does it mean that the nature of the cathode ray is a particle or wave?", need to be addressed in depth. When the conceptual understanding is properly established, the meaning of the controversy and the process that occurred among scientists at that time can be fully understood.

Therefore, considering research questions, conclusions of this study are as follows. First, controversial issues related to the structure of the atom are distributed from conceptual conflicts, to procedural conflicts, even to a beliefs conflict. Teachers, therefore, 
will be able to use controversial issues in class by figuring out whether to focus on conceptual problems or procedural problems or beliefs problems. For example, in case of T1 issue which is about the nature of cathode rays in Thomson's experiment, the teacher can discuss with students around concepts of wave and particle. In this case, it needs to understand what particle is, and what wave is clearly. In addition, it is necessary to understand what each of the claims of whether the cathode ray is a particle or wave means. To do this, physics teachers need to have a rich understanding of the key concepts of the controversies, including background context and philosophical foundations. This shows that even in teacher education, it is necessary to educate students to understand the background and meaning of concepts more deeply than to transfer the resulting knowledge of physics concepts, as "rhetoric of conclusions". In this way, teachers will be able to deal with controversial issues about the structure of the atom, from conceptual problems to beliefs problems underlying science.

Second, as shown in this study, using the framework of knowledge and belief, the conflict structure of controversial issues that appeared in science history can be analyzed in more detail. In other words, the framework of knowledge and belief can be a good tool for exploring, analyzing, and selecting meaningful historical controversies. Specifically, through this analysis, it is possible to grasp what kind of conflict structure of controversial issues that appear in history of science: for instance, a conceptual level or a procedural level or beliefs level, etc. The components of framework of knowledge and belief - conceptual / procedural / contextual knowledge and belief - are not just related to specific contents, but they are general in most educational context. Therefore, the framework proposed in this study can be a tool that can be generally used to analyze science historical controversies on theories or concepts of physics on various topics.

Moreover, the results of this study also have some implications for science teaching and science education research. First, it is possible to provide more specific guideline when using history of science, especially controversial issues, in science class. In this study, it was focused on that the controversy is a conflict situation and attempted to grasp elements causing the conflict situation. And by analyzing and classifying the aspect of the conflict, teachers will be able to grasp the structure and types of scientific historical controversies and design lessons that cover various knowledge-belief domains. We think that this is to provide a guide for science teachers to make their lessons richer by utilizing the scientific historical controversies. Second, the result of the presented in this study has a significant implication for science education research, which can help to understand scientific historical controversies related to other topics besides the structure of the atom, and to select educationally meaningful controversies. Through this analysis, science teachers and researchers will be able to explore and analyze controversies in history of science on their own and use them in class. And historical controversies with educational meanings on various topics will be able to be studied and utilized in abundance. In addition, the method and result of this study can be applied in various ways, such as analyzing science textbooks, and developing science textbooks, which could better represent the structure of controversy as experienced by scientists in their scientific practices.

\section{REFERENCES}

Archila, P. A., Molina, J., \& de Mejía, A. T. (2020). Using historical scientific controversies to promote undergraduates' argumentation. Science and Education, 29(3), 647-671. https:/ / doi.org/10.1007/ s11191-020-00126-6

Dickerson, R. E., Gray, H. B., Darensbourg, M. Y., \& Darensbourg, D. J. (1984). Chemical principles (4th ed.). CA: Benjamin/Cummings.

Garritz, A. (2013). Teaching the philosophical interpretations of quantum mechanics and quantum chemistry through controversies. Science and Education, 22(7), 1787-1807. https://doi.org/ $10.1007 / \mathrm{s} 11191-012-9444-x$

Hodson, D. (1988). Toward a Philosophically more valid science curriculum. Science Education, 72(1), 19-40. https:/ / doi.org/10.1002/sce.3730720103

Hodson, D. (2009). Teaching and learning about science: language, theories, methods, history, traditions and values. Rotterdam: Sense Publishers.

Jenkins, E. (1989). Why the history of science? In M. Shortland and A. Warwick (Eds.), Teaching the history of science. Basil Blackwell.

Jones, B. F., Pierce, J., \& Hunter, B. (1988-1989). Teaching students to construct graphic representations. Educational Leadership, 46(4), 20-25.

Justi, R. \& Mendonça, P. C. C. (2016). Discussion of the controversy concerning a historical event among pre-service teachers: Contributions to their knowledge about science, their argumentative skills, and reflections about their future teaching practice. Science and Education, 25(7-8), 795-822. https:/ / doi.org/10.1007/s11191-016-9846-2

Kim, S. Y., \& Irving, K. E. (2010). History of science as an instructional context: Student learning in genetics and nature of science. Science and Education, 19(2), 187-215. https://doi.org/10.1007/s11191-0099191-9

Lee, G. \& Yi, J. (2013). Where cognitive conflict arises from?: The structure of creating cognitive conflict. International Journal of Science and Mathematics Education, 11(3), 601-623. https:/ / doi.org/10.1007/ s10763-012-9356-x 
Machamer, P., Pera, M., \& Baltas, A. (2000). Scientific controversies: An introduction. In P. Machamer, M. Pera \& A. Baltas (Eds.), Scientific controversies: Philosophical and historical perspectives (pp. 3-17). New York: Oxford University Press.

Matthews, M. R. (2015). Science teaching: The role of history and philosophy of science 20th anniversary revised and expanded edition. New York: Routledge.

Nahum, K. (2001). Scientific controversies in teaching science: The case of Volta. Science and Education, 10(1-2), 33-49. https://doi.org/10.1023/A: 1008760521211

Niaz, M. (1998). From cathode rays to alpha particles to quantum of action: A rational reconstruction of structure of the atom and its implications for chemistry textbooks. Science Education, 82(5), 527552. https:/ / doi.org/10.1002/(SICI)1098237X(199809)82:5<527::AID-SCE1>3.0.CO;2-B

Niaz, M. (2009). Critical appraisal of physical science as a human enterprise: dynamics of scientific progress. Dordrecht: Springer.

Niaz, M. \& Coştu, B. (2009). Presentation of atomic structure in Turkish general chemistry textbooks.
Chemistry Education Research and Practice, 10(3), 233240. https://doi.org/10.1039/B914503F

Niaz, M. (2010). Are we teaching science as practiced by scientists? American Journal of Physics, 78(1), 5-6. https: / / doi.org/10.1119/1.3238470

Niaz, M. \& Rodríguez, M. A. (2002). Improving learning by discussing controversies in 20th century physics. Physics Education, 37(1), 59-63. https://doi.org/ 10.1088/0031-9120/37/1/308

Niaz, M., Kwon, S., Kim, N., \& Lee, G. (2013). Do general physics textbooks discuss scientists' ideas about atomic structure? A Case in Korea. Physics Education, 48(1), 57-64. https://doi.org/10.1088/ 0031-9120/48/1/57

Rodríguez, M. A. \& Niaz, M. (2004). A reconstruction of structure of the atom and its implications for general physics textbooks: A history and philosophy of science perspective. Journal of Science Education and Technology, 13(3), 409-424. https:// doi.org/10.1023/B:JOST.0000045468.49500.3b

Sequeira, M., \& Leite, L. (1991). Alternative conceptions and history of science in physics teacher education. Science Education, 75(1), 45-56. https://doi.org/ 10.1002 / sce. 3730750105

\section{http://www.ejmste.com}

